\title{
OCORRÊNCIA DE ANTICORPOS CONTRA O HERPESVÍRUS EQUINO E VIRUS DA ARTERITE EQUINA EM REBANHOS EQUINOS DO ESTADO DO RIO DE JANEIRO
}

\section{OCCURRENCE OF ANTIBODIES AGAINST EQUINE HERPESVIRUS AND EQUINE ARTERITIS VIRUS IN HORSE HERDS OF RIO DE JANEIRO STATE, BRAZIL}

\author{
Kathryn Anne Ford Diaz ${ }^{1}$ \\ Silvia de Oliveira Hübner² \\ Gilberto D'ávila Vargas² \\ Geferson Fischer ${ }^{2}$ \\ Walter Lilenbaum ${ }^{3}$ \\ Marcelo de Lima ${ }^{2^{*}}$ \\ 1Universidade Federal Fluminense, Programa de Pós-graduação em Medicina Veterinária, Niterói, RJ, \\ Brasil. \\ ${ }^{2}$ Universidade Federal de Pelotas, Faculdade de Veterinária, RS - \\ ${ }^{3}$ Professor, Instituto Biomédico, UFF, Niterói, RJ \\ *Autor para correspondência - mdelima.ufpel@gmail.com
}

\section{Resumo}

A infecção pelo herpesvírus equino (EHV) e o vírus da arterite equina (EAV) tem sido associada a perdas econômicas importantes para a equideocultura em nível mundial. Estudos sorológicos têm demonstrado a circulação destes agentes no Brasil. O presente trabalho teve como objetivo principal estudar a ocorrência de anticorpos específicos contra o EAV e EHV em cavalos oriundos de diferentes regiões do estado do Rio de Janeiro. Para este propósito, foram coletadas amostras de soro de 581 animais não vacinados e de 44 éguas provenientes de um plantel vacinado regularmente contra a rinopneunonite equina. Todas as amostras foram submetidas ao teste de soroneutralização para a pesquisa de anticorpos específicos contra cada um dos vírus. Os resultados demonstraram 29,6\% (172/581) de animais soropositivos para o EHV (títulos entre 2 e $\geq 256)$ e 0,79\% (05/630) para o EAV (títulos entre 2 e 4.096). Considerando a sorologia positiva em animais não imunizados, os achados demonstram a indução de anticorpos específicos após exposição natural aos respectivos vírus, indicando uma possível circulação desses agentes nos rebanhos analisados.

Palavras-chave: anticorpos; EAV; EHV; equinos; soroneutralização.

\begin{abstract}
Infections by equine herpesvirus (EHV) and equine arteritis virus (EAV) have been associated with important economic losses for the equine industry worldwide. Serological studies have indicated the presence of these agents in Brazil. The aim of this study was to evaluate the occurrence of specific
\end{abstract}


antibodies against EAV and EHV in horse herds from different regions of Rio de Janeiro state. For this purpose, serum samples of 581 non-vaccinated animals and 44 breeding mares regularly vaccinated against equine rhinopneumonitis were collected. All samples were submitted to the virus neutralization test for the detection of specific antibodies to each virus. Results showed $29.6 \%$ $(172 / 581)$ of seropositive animals for EHV (titers between 2 and $\geq 256)$ and $0.79 \%(5 / 630)$ for EAV (titers between 2 and 4,096). Considering the non-vaccinated animals, these findings demonstrated that specific antibodies were induced after natural exposure to the respective viruses, suggesting a probable circulation of these agents in the studied herds.

Keywords: antibodies; EAV; EHV; horses; virus neutralization.

Recebido em: 20 agosto de 2013

Aceiro em: 25 março 2015

\section{Introdução}

O Brasil possui o quarto maior rebanho de equinos do mundo com estimados 5,5 milhões de animais $^{(1,2)}$. Este número expressivo de animais representa a importância da equideocultura nacional do ponto de vista social e econômico. As enfermidades de etiologia viral estão entre as mais importantes na espécie equina, sendo o herpesvirus equino tipo 1 (EHV-1) e o vírus da arterite equina (EAV) reconhecidamente importantes por causarem quadros clínicos respiratórios, reprodutivos e, menos frequentemente, sinais neurológicos ${ }^{(3)}$.

O herpesvirus equino tipo 1 pertence à subfamília Alphaherpesvirinae, gênero Varicellovirus; possui distribuição mundial e está associado a abortamentos (particularmente no terço final de gestação) além de sinais clínicos neurológicos e respiratórios ${ }^{(4)}$. Uma característica marcante desse vírus é o estabelecimento de latência em gânglios neuronais e em linfócitos T como uma estratégia de evasão do sistema imunológico do hospedeiro.

$\mathrm{O}$ vírus da arterite equina (EAV) é o protótipo do gênero Arterivirus, família Arteriviridae ${ }^{(5)}$. É um agente causador de lesões no endotélio dos vasos sanguíneos, além de quadros respiratórios e ocorrência de abortamentos $^{(6)}$. A enfermidade possui distribuição mundial e está associada a prejuízos econômicos para a indústria equina que incluem, dentre outras coisas, restrições internacionais na importação de sêmen e animais soropositivos ${ }^{(7)}$.

A maioria das vacinas contendo antígenos do EHV-1 é comercializada como vacinas polivalentes, associadas com antígenos do EHV-4, EIV (vírus da influenza equina), tétano, EEEV e WEEV (vírus da encefalite equina leste e oeste). No Brasil, todas as vacinas licenciadas e aprovadas pelo Ministério da Agricultura, Pecuária e Abastecimento (MAPA) para o controle das infecções pelo EHV-1 são inativadas. Por outro lado, não existem vacinas disponíveis contra a arterite viral equina no mercado nacional. Apesar de estudos epidemiológicos demonstrarem uma provável circulação do agente no país, o registro e a comercialização de imunógenos específicos somente será possível após o reconhecimento oficial da doença pelas autoridades e órgãos sanitários oficiais.

Embora alguns estudos sorológicos de caráter regional já tenham demonstrado a distribuição do EHV-1 e do EAV no território nacional, não existem dados disponíveis sobre a circulação e/ou presença de anticorpos específicos contra esses vírus em rebanhos equinos do estado do Rio de Janeiro. Neste sentido, este trabalho teve como objetivo investigar a ocorrência de anticorpos 
específicos contra o herpesvírus equino e vírus da arterite equina, pela técnica de soroneutralização, em equinos não vacinados provenientes das regiões Metropolitana e Serrana do estado do Rio de Janeiro.

\section{Material e Métodos}

Foram coletadas 581 amostras de soro provenientes de éguas não-vacinadas contra o EAV e o EHV-1, distribuídas em 13 propriedades de oito municípios do estado do Rio de Janeiro (Seropédica, Paracambi, Japeri, Queimados, Itaboraí, Cachoeiras de Macacu, Três Rios, Friburgo e São Sebastião do Alto), entre os anos 2011 e 2012. Foram coletadas ainda 49 amostras de soro provenientes de uma propriedade com vacinação anual contra rinopneumonite equina, na cidade de Teresópolis, totalizando 630 amostras.

O sangue total foi coletado por meio de venopunção jugular em tubos estéreis sem anticoagulante e, após a retração do coágulo, o soro foi separado e alíquotas foram devidamente identificadas e armazenadas em tubos plásticos de microcentrífuga a $-20{ }^{\circ} \mathrm{C}$ até o momento da realização dos testes. Todas as amostras de soro foram submetidas à técnica de soroneutralização (SN) para a pesquisa de anticorpos específicos contra o EHV-1 e EAV. Resumidamente, os soros em diferentes diluições (1:2 até 1:256 - recíproca da maior diluição do soro utilizada no presente estudo) foram distribuídos em microplacas de poliestireno de 96 cavidades juntamente com uma dose constante (100 TCID $_{50}$ - tissue culture infectious dose) da cepa viral padrão, previamente titulada. Após um período de incubação de $1 \mathrm{~h}$ em estufa de $\mathrm{CO}_{2}$ a $37{ }^{\circ} \mathrm{C}$, uma suspensão de células da linhagem RK13 foi adicionada. As placas contendo a mistura soro-vírus-células foram então incubadas a $37{ }^{\circ} \mathrm{C}$ em atmosfera com $5 \%$ de $\mathrm{CO}_{2}$ por 72-96 h.

Soros hiperimunes produzido em coelhos (gentilmente cedidos pelo Dr. Luiz Kreutz, UPF, RS) foram usados como controles positivos em todas as reações. $\mathrm{O}$ monitoramento da reação foi realizado diariamente em um microscópio ótico invertido até o momento da leitura final. O título de anticorpos específicos presente na amostra foi dado pela recíproca da diluição do soro capaz de prevenir o efeito citopático (ECP) característico de cada um dos vírus na monocamada de células. As amostras que apresentaram títulos $\geq 2$ foram consideradas positivas.

O presente estudo foi aprovado pelo Comitê de Ética no Uso de Animais (CEUA) da UFF (número de registro: $185 / 12$ ).

\section{Resultados e Discussão}

Os resultados dos testes de soroneutralização demonstraram que 29,6\% (172/581) das amostras analisadas apresentaram resultado positivo para a presença de anticorpos específicos contra o herpesvírus equino (EHV) (Tabela 1). Animais reagentes ao EHV foram detectados em praticamente todas as propriedades analisadas, porém os maiores percentuais foram observados em rebanhos localizados nos municípios de São Sebastião do Alto $(n=53)$ e Seropédica $(n=32)$.

Para uma análise mais detalhada dos resultados observados, as amostras consideradas positivas foram agrupadas em três categorias: títulos baixos (2 até 16), médios (32 até 128) e altos ( $\geq 256$ ). Do total de amostras reagentes na $\mathrm{SN}$ contra o EHV, uma predominância de títulos baixos 
correspondendo a 79,7\% (136/172) foi observada. Títulos classificados como médios foram observados em 15,7\% (27/172), enquanto que títulos considerados baixos foram detectados em $5,23 \%$ (9/172) do total de amostras positivas (Figura 1).

Tabela 1: Total de animais não vacinados e reagentes no teste de soroneutralização frente ao herpesvírus equino (EHV) e o vírus da arterite equina (EAV)

\begin{tabular}{lll}
\hline & EHV -1 (\%) & EAV (\%) \\
\hline Negativo $^{1}$ & $401(69,01)$ & $615(97,63)$ \\
Positivo $^{2}$ & $172(29,60)$ & $5(0,79)$ \\
Tóxico $^{3}$ & $8(1,39)$ & $10(1,58)$ \\
\hline Total & $581 *$ & 630
\end{tabular}

* Animais vacinados contra o EHV foram desconsiderados

1 título $<2$

${ }^{2}$ presença de anticorpos neutralizantes

${ }^{3}$ efeito tóxico do soro impediu a interpretação do resultado final do teste

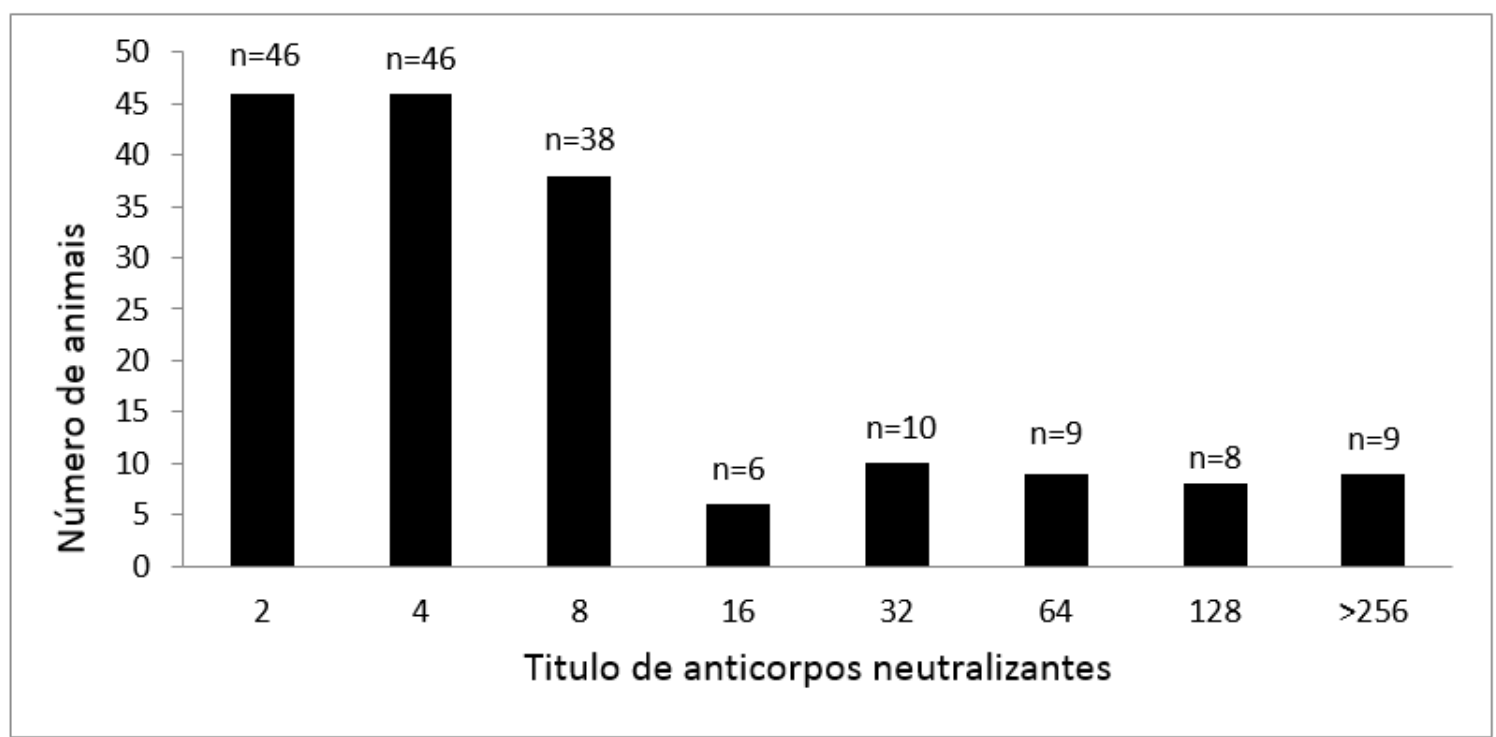

Figura 1: Distribuição dos títulos de anticorpos neutralizantes contra o EHV-1 em equinos não-vacinados e oriundos de diferentes municípios do Estado do Rio de Janeiro. O título de anticorpos corresponde à recíproca da diluição do soro capaz de prevenir a produção de ECP na monocamada de células RK13.

A presença de anticorpos específicos contra o herpesvírus equino em animais não vacinados tem importância epidemiológica tendo em vista o estabelecimento de infecções latentes após infecção primária $^{(3)}$. Apesar de a enfermidade aguda causada pelo EHV em equinos, geralmente, resolver-se em poucas semanas após a infecção primária, é comum o estabelecimento da latência seguida de episódios de reativações com recrudescência clínica e excreção viral. Assim, os animais latentemente infectados são portadores assintomáticos capazes de eliminar o vírus em grandes concentrações após situações de estresse, caracterizando um importante mecanismo de disseminação viral dentro dos rebanhos ${ }^{(4,8)}$. 
Apesar de quase todos os rebanhos avaliados neste estudo apresentarem animais reagentes ao EHV1, somente em quatro rebanhos havia um histórico prévio de abortamentos (totalizando 12 animais). O baixo índice de abortamentos nestes rebanhos específicos pode ser atribuído à ocorrência de infecções subclínicas ou com sinais clínicos leves associados à infecção pelo EHV. Reações cruzadas com o EHV-4, que não possui característica abortigênica, são muito comuns e devem ainda ser consideradas. Nenhum desses 12 animais apresentou sorologia positiva contra o EAV, porém a presença de anticorpos específicos contra o EHV (título de 8) foi detectada em 2 éguas receptoras de embrião pertencentes ao mesmo rebanho. A presença de sorologia positiva nesses animais poderia sugerir uma possível associação do herpesvírus equino com os episódios de abortamentos. Entretanto, o diagnóstico definitivo somente seria possível após a realização da sorologia pareada para avaliar o aumento dos títulos de anticorpos específicos contra o EHV, ou ainda pelo isolamento viral a partir de secreções ou de tecidos do feto abortado.

Tabela 2: Resultados dos testes de soroneutralização em soro sanguíneo de equinos criados no estado do Rio de Janeiro para o herpesvírus equino e para o vírus da arterite equina, agrupados segundo a procedência das amostras

\begin{tabular}{|c|c|c|c|c|c|c|c|}
\hline \multirow[b]{2}{*}{ Municipio } & \multirow[b]{2}{*}{ Total } & \multicolumn{3}{|c|}{ EHV } & \multicolumn{3}{|c|}{ EAV } \\
\hline & & Positivos & Negativos $^{1}$ & Total* & Positivos & Negativos $^{1}$ & Total* \\
\hline $\begin{array}{l}\text { Cachoeiras } \\
\text { de Macacu }\end{array}$ & 98 & 26 & 67 & 93 & 01 & 91 & 92 \\
\hline $\begin{array}{l}\text { Nova } \\
\text { Friburgo }\end{array}$ & 02 & 0 & 02 & 02 & 0 & 02 & 02 \\
\hline Itaboraí & 55 & 22 & 33 & 55 & 0 & 55 & 55 \\
\hline Japeri & 07 & 05 & 02 & 07 & 01 & 06 & 07 \\
\hline Paracambi & 46 & 07 & 39 & 46 & 0 & 46 & 46 \\
\hline Queimados & 27 & 08 & 19 & 27 & 0 & 27 & 27 \\
\hline São & & & & & & & \\
\hline Sebastião & 122 & 53 & 66 & & 0 & 121 & \\
\hline do Alto & & & & 119 & & & 121 \\
\hline Seropédica & 115 & 32 & 83 & 115 & 0 & 115 & 115 \\
\hline Teresópolis & 49 & $---^{2}$ & $---^{2}$ & $--^{2}$ & 02 & 44 & 46 \\
\hline Três Rios & 109 & 19 & 90 & 109 & 01 & 108 & 109 \\
\hline *Soros tóxicos & ram des & derados & & & & & \\
\hline
\end{tabular}

Estudos sorológicos prévios já demonstraram a ampla distribuição do herpesvírus equino no Brasil, com percentuais de soropositividade variando desde 4,5\% (67/1.506) no Rio Grande do Sul ${ }^{(9)}$ até 45,45\% (230/506) no Pará(8). O percentual de animais soropositivos para o EHV neste estudo $(29,6 \%)$ foi semelhante aos resultados observados em São Paulo de 26 e $27,2 \%{ }^{(10,11)}$ e 33,4\% ${ }^{(12)}$.

Embora não tenha sido o foco principal do presente estudo, é importante observar os resultados obtidos com os 44 animais pertencentes a um rebanho regularmente vacinado contra a 
rinopneumonite equina, conforme as recomendações do fabricante do imunógeno. Foi observado que os títulos de anticorpos neutralizantes específicos contra o EHV variaram de 4 até $\geq 256$ e foram detectados em $50 \%$ dos animais (22/44). Resultados similares aos observados no presente estudo foram descritos em um estudo de campo na Austrália, onde foi avaliada a soroconversão de 159 éguas e 101 potros após imunização com uma vacina contendo antígenos inativados do EHV-1. Mesmo seguindo criteriosamente as orientações do fabricante, menos de $30 \%$ das éguas e menos de $50 \%$ dos potros responderam à vacinação naquela ocasião ${ }^{(13)}$.

Em relação aos testes sorológicos realizados com o EAV, foi observado que 5 amostras de soro foram consideradas positivas, representando 0,79\% (5/630) do total de amostras analisadas. Os animais soropositivos foram provenientes de rebanhos localizados no município de Três Rios, Japeri, Cachoeiras de Macacu e Teresópolis, sendo que neste último município títulos elevados de anticorpos neutralizantes (1.024 e 4.096) específicos contra o EAV foram detectados em 2 animais (Tabelas 1 e 2).

O percentual de animais soropositivos nesse estudo $(0,79 \%)$ foi muito similar ao encontrado por Bello et al. ${ }^{(14)}$ em MG $(0,85 \%)$ e inferior aos $2,2 \%$ detectados no $\operatorname{RS}^{(9)}$ e dos $18,2 \%{ }^{(15)}$ e $5,7 \%{ }^{(16)}$ em São Paulo. Esses índices superiores de animais soropositivos encontrados em SP pode ser um reflexo da grande movimentação de animais importados nesse estado, que consiste no maior criador e importador da raça Quarto de Milha no Brasil, além da importação de animais de salto e provas hípicas. No Rio Grande do Sul, a proximidade da fronteira com outros países, particularmente com a Argentina, poderia facilitar a entrada e/ou trânsito de animais infectados sem um maior controle da fiscalização. Os estados de Minas Gerais e Rio de Janeiro têm como maioria, no seu plantel de equinos, as raças nacionais Mangalarga Marchador e Campolina, diminuindo as possibilidades de entrada do EAV nos rebanhos pela importação de sêmen ou de animais vivos.

Destes cinco animais $(0,79 \%)$ positivos para EAV, somente uma égua apresentou sorologia positiva também para o herpesvírus equino (titulo de 8). As éguas eliminam o vírus naturalmente após uma infecção aguda e desenvolvem uma resposta imune efetiva na proteção contra reinfecções ${ }^{(17)}$. No presente estudo, foram observados títulos de anticorpos neutralizantes relativamente baixos (entre 2 e 4) em três das cinco amostras positivas testadas, sugerindo uma infecção prévia pelo EAV antes do ingresso desses animais nas respectivas propriedades. Paralelamente, títulos elevados de anticorpos (1.024 e 4.096) foram observados em duas das cinco amostras positivas. Esses altos níveis de anticorpos são sugestivos de uma infecção recente considerando a estimulação imunológica devido à replicação viral. Títulos relativamente altos de anticorpos neutralizantes $(\geq 512)$ são geralmente induzidos em animais experimentalmente infectados com cepas do $\mathrm{EAV}^{(18)}$ ou imunizados com vacinas atenuadas ${ }^{(19)}$.

Segundo o histórico desses animais, não foi possível estabelecer o motivo dos altos títulos de anticorpos contra o EAV. Uma das éguas (apresentando título 1.024) não pertencia à propriedade onde foi coletada a amostra, estando hospedada no local durante a estação reprodutiva até a confirmação de sua prenhez, o que levou cerca de três meses, quando a mesma retornou à sua propriedade de origem, próximo ao local de coleta. Não foram obtidas maiores informações acerca do histórico dessa égua ou de outros animais dessa propriedade, sendo interessante uma avaliação sorológica do plantel para maiores esclarecimentos em relação à circulação do EAV no local.

O outro animal (título 4.096) foi importado da Europa para o estado de São Paulo e posteriormente transferido para o RJ cerca de três meses antes da coleta da amostra de soro utilizada neste estudo. Há a possibilidade de que a referida égua tenha sido vacinada em seu país de origem na Europa, 
porém a manutenção destes títulos elevados por um período prolongado de tempo é pouco provável. Por outro lado, infecções prévias (e não recentes) não podem ser descartadas pelo fato de que animais infectados naturalmente pelo EAV desenvolvem anticorpos específicos que permanecem detectáveis por vários anos. Infecções persistentes são bem documentadas em garanhões ${ }^{(7)}$ e poderiam justificar, embora que parcialmente, a indução de títulos altos de anticorpos pela estimulação constante do sistema imunológico devido à replicação viral. Essa égua foi inseminada com sêmen congelado e importado de um garanhão de alto valor zootécnico, negativo para EAV, e que tem seu sêmen monitorado constantemente. Uma outra égua da propriedade também foi inseminada com o mesmo sêmen e não apresentou títulos anti-EAV no teste de SN.

É importante salientar que as duas éguas com alto título foram inseminadas com sêmens distintos, não tiveram contato direto e foram separadas em lotes diferentes. Os animais permaneceram com outros animais da propriedade, sem relatos de quadros clínicos respiratórios ou abortivos desde a época da coleta até o presente momento. Esses dados são consistentes com o fato de que o estado de portador ainda não foi identificado em fêmeas equinas ${ }^{(7)}$.

Diante dos dados disponíveis, não foi possível identificar a causa precisa desses altos títulos encontrados nesses animais. Cabe ainda destacar que não foi possível uma avaliação do histórico das éguas antes de seu ingresso nas propriedades, dificultando uma investigação epidemiológica mais detalhada em relação à provável origem da infecção desses animais pelo EAV.

Apesar do baixo percentual de animais positivos no teste de SN contra o EAV, os resultados sugerem uma possível circulação do agente em equinos do estado do Rio de Janeiro, já que a presença de anticorpos específicos em animais não vacinados é um indicativo de exposição prévia ao agente. Considerando que a apresentação assintomática da infecção pelo EAV é relativamente comum, medidas de profilaxia e controle devem ser tomadas a fim de se evitar a disseminação viral e o surgimento de surtos da enfermidade no estado do Rio de Janeiro e em nível nacional.

\section{Conclusão}

O presente trabalho representa a primeira investigação da ocorrência anticorpos específicos frente ao herpesvírus equino (EHV) e o vírus da arterite equina (EAV) em rebanhos equinos não vacinados e distribuídos em diferentes regiões do estado do Rio de Janeiro. Os resultados obtidos são um indicativo da exposição prévia desses animais ao EHV e EAV, demonstrando a circulação desses agentes em rebanhos equinos do estado do RJ, e podem auxiliar na implementação de estratégias de controle e prevenção dessas enfermidades, além de uma maior vigilância desses agentes infecciosos em nível regional.

\section{Agradecimentos}

À equipe do Laboratório de Virologia da UFF e do Laboratório de Virologia e Imunologia da UFPel pelo apoio técnico, e à CAPES pelo suporte financeiro.

\section{Referências}


1. Instituto Brasileiro de Geografia e Estatística - IBGE. Produção da pecuária municipal - 2011. [Internet] vol.39. Available from: http://www.ibge.gov.br/home/

2. FAO Agricultural data - FAOSTAT 2010 [Internet], cited 2012 Sep 9. Available from: http://faostat3.fao.org/home/index.html\#

3. Ostlund EN. The equine herpesviruses. Veterinary Clinics of North America: Equine Practice. 1993;9(2):283-294.

4. Patel JR, Heldens J. Equine herpesvírus 1 (EHV-1) and 4 (EHV-4) epidemiology, disease and, immunoprophylaxis: a brief review. Veterinary Journal. 2005;170(1):14-23.

5. Snijder EJ, Meulenberg JJM. The molecular biology of arteriviruses. Journal of General Virology. 1998;79(3):961-979.

6. Balasuriya UB, Go YY, MacLachlan NJ. Equine arteriris virus. Veterinary Microbiology. 2013;167(12):93-122.

7. Timoney PJ. Equine Viral Arteritis. Equine Respiratory Diseases. International Veterinary Information Service (IVIS), 2002. [Internet] Available from: www.ivis.org. Acesso em 10 de outubro de 2012.

8. Pena LJ, Pena DA, Barrios PR, Dale R, Lamego MRA, Moraes MP. Levantamento soro-epidemiológico da infecção pelo vírus da Anemia Infecciosa Equina, da Influenza Equina-2 e do Herpesvirus Equino-1 em rebanhos do sul do Estado do Pará, Brasil. Brazilian Journal of Veterinary Research and Animal Science. 2006;43(4):537-542.

9. Diel DG, Almeida SR, Weiblen R, Frandoloso R, Anziliero D, Kreutz LC, Groff FHS, Flores EF. Prevalência de anticorpos contra os vírus da influenza, da arterite viral e herpesvirus em equinos do Estado do Rio Grande do Sul, Brasil. Ciência Rural. 2005;36(5):1467-1473.

10. Cunha EMS, Ferrari CIL, Lara CCSH, Silva LHQ. Presença de anticorpos contra o herpesvirus equino (HVE-1) em equinos do noroeste do estado de São Paulo. Arquivos do Instituto Biológico. 2002; 69(1):1-5.

11. Cunha EMS, Villalobos EMC, Nassar AFC, Lara MCCSH, Peres NF, Palazo JPC, Silva A, De Stefano E, Pino FA. Prevalência de anticorpos contra agentes virais em equídeos no sul do Estado de São Paulo. Arquivos do Instituto Biológico. 2009;76(2):165-171.

12. Lara MCCSH, Cunha EMS, Nassar AFC, Gregory L, Birgel EH, Fernandes WR. Ocorrência do herpesvirus equino1 (HVE-1) em cavalos criados no estado de São Paulo, Brasil. Ars Veterinária. 2003;19(3):254-259.

13. Foote CE, Raidal SL, Pecenpetelovska G, Wellington JE, Whalley JM. Inoculation of mares and very young foals with EHV-1 glycoproteins D and B reduces virus shedding following respiratory challenge with EHV-1. Veterinary Immunology and Immunopathology. 2006;111(2):97-108.

14. Bello ACPP, Cunha AP, Braz GF, Lara MCSH, Reis JKP, Haddas JPH, Rocha MA, Leite RC. Frequency of equine viral arteritis in Minas Gerais State, Brazil. Arquivo Brasileiro de Medicina Veterinária e Zootecnia. 2007;59(4):1077-1079.

15. Lara MCCSH, Fernandes WR, Timoney, PJ, Birgel, EH. Prevalência de anticorpos antivírus da arterite dos equinos em cavalos criados no Estado de São Paulo. Arquivo Brasileiro de Medicina Veterinária e Zootecnia. 2002;54(3):223-227.

16. Braga PRC, Lara MCCSH, Dias A, Cunha EMS, Villalobos EMC, Ribeiro MG, Borges AS. Soroprevalência da arterite viral equina em mesorregiões paulistas entre 2007 e 2008. Semina: Ciências Agrárias. 2012;33(4):1501-1506. 
17. Hostnik P, Klobucar, I, Malovrh T, Mankoc S, Toplak I, Grom J. Control of equine arteritis virus (EAV) on a stud farm. Veterinarsky Arhiv. 2011;81(2):175-180.

18. Maclachlan NJ, Balasuriya UBR, Hedges JF, Schweidler TM, McCollum WH, Timoney PJ, Hullinger PJ, Paton, JF. Serologic response of horses to the structural proteins of equine arteritis virus. Journal of Veterinary Diagnostic Investigation. 1998;10(3):229-236.

19. Summers-Lawyer KA, Young Go Y, Lu Z, Timoney PJ, McCue PM, Zhang J, Schuck K, Bruemmer J. Response of stallions to primary immunization with a modified live equine viral arteritis vaccine. Journal of Equine Veterinary Science. 2011;31(1):129-138. 